\title{
Primary sector volatility and default risk in Indonesia
}

\author{
D.E. Allen ${ }^{\text {a }}$, R.R. Boffey ${ }^{\text {a }}$, \\ ${ }^{a}$ Edith Cowan University, Western Australia \\ a.kramadibrata@ecu.edu.au
}

\begin{abstract}
The Indonesian market is a critical market to the South East Asian region, being that region's largest economy. The primary sectors of the Indonesian economy, incorporating Agriculture and Mining, are of critical importance to the country, representing approximately one quarter of GDP and providing nearly $40 \%$ of the nation's employment. Mining and Agriculture stock returns significantly outperformed the Indonesian Stock Exchange (IDX) composite index in the five years leading up to Global Financial Crisis (GFC), and experienced savage falls during the GFC. Against this background, we examine the market and credit risk of these sectors during the pre-GFC, GFC and post-GFC periods.

Market risk is measured using Value at Risk (VaR) and Conditional Value at Risk (CVaR). VaR is a popular metric which measures potential losses over a specific time period, up to a selected threshold. A key downside of this metric is that it says nothing of the extreme risk beyond VaR, which is a major limitation for this study, given the extreme volatility experienced by the primary sectors in Indonesia over the studied period. We therefore also use CVaR, which measures the extreme risk beyond VaR.
\end{abstract}

For credit risk, we use the Merton-KMV Distance to Default (DD) metric, as well as our own Conditional $\mathrm{DD}$ (CDD) metric to measure extreme default risk. The key advantage that the Merton-KMV model has over other credit models, it that it incorporates fluctuating asset values. This makes it more responsive to changes in market conditions than most other credit models which remain static between rating periods. The importance of fluctuating asset values in measuring credit risk has been raised by the Bank of England (2008), who make makes the point that not only do asset values fall in times of uncertainty, but rising probabilities of default make it more likely that assets will have to be liquidated at market values. Similar to $\mathrm{VaR}$, the Merton-KMV model has deficiencies in that it uses the standard deviation of asset value fluctuations, which tends to smooth the volatility and does not capture tail risk over that period. Our CDD model is able to measure risk at the most extreme times of the economic cycle, which is precisely when firms are most likely to fail, and when banks are most likely to experience high credit losses.

We find that market risk for the primary industries is significantly higher than the broader market, and that there is a relatively higher difference between $\mathrm{VaR}$ and $\mathrm{CVaR}$, indicating a higher tail risk. Mining, in particular has a higher market risk than other Indonesian sectors. Interestingly, this is not the case with credit risk, where the risk for Agriculture is lower than the overall market, and the risk for Mining is not significantly different to the overall market. This is because the leverage of a firm is a key component of the Merton-KMV model and we find the leverage for the Agriculture and Mining industries to be far more conservative than the broader market. This means that these primary sectors are able to withstand relatively higher levels of asset volatility.

These findings can benefit both lenders and investors when considering the inclusion of these sectors in their investment or loan portfolio mix.

Keywords: Agriculture, mining, value at risk, distance to default 


\section{INTRODUCTION}

This study examines the relative sharemarket and credit risk of the Indonesian primary sectors of Agriculture and Mining. These two sectors experienced substantial growth in sharemarket returns during the early GFC, but this was severely decimated over the GFC, recovering strongly thereafter. High returns of course, are usually accompanied by high risk. The period examined is 2005-2011, which covers a good spread of economic conditions, encompassing pre-GFC, GFC, and post GFC periods. Market risk is measured using Value at Risk (VaR) and Conditional Value at Risk (CVaR) which measures tail risk. Credit Risk is measured using the Merton-KMV Distance to Default (DD) model as well our own Conditional DD (CDD) model which measures tail credit risk. The aim is to determine whether the Agriculture and Mining Sectors have higher or lower market and credit risk than the Indonesian market as a whole. This comprehensive study, using four different metrics is important to both investors and lenders in considering the inclusion of these sectors in their portfolios.

To place our study in context, this section will provide some background on Indonesia, its economy and the importance of the Agriculture and Mining sectors. The performance of these two sectors on the Indonesian sharemarket (IDX) will also be discussed.

\subsection{Background on the Indonesian Economy and its Primary Sectors}

Indonesia is the world's fourth most populous country, with a population of 240 million. It has the largest economy in South East Asia. The country has a Baa3 (investment grade) Moody's sovereign credit rating. Indonesia's economy and sharemarket outperformed most developed global countries during the GFC and its aftermath. In the 6 years to 2012, it experienced GDP growth exceeding 6\% each year, except for a $4.6 \%$ growth in 2009. Figure 1 shows how The IDX has also strongly outperformed the US S\&P 500 since 2004.

The literature provides some insight into the performance of the Indonesian economy over the GFC. Siregar, Hasanah, and Noer (2012) feel that while there were impacts of the GFC, such as a sharp downturn in the share market and a reduction in commodity prices which affected the Agricultural sector, this impact was reduced through prompt policy responses by the government and monetary authorities, resulting in a rapid recovery. The authors believe that the rapid recovery was also due to the fact that the financial instruments responsible for triggering the GFC were not a dominant component of the Indonesian financial markets, and that the slowdown in Indonesia was predominantly due to indirect effects of the crisis and panic by investors. The authors report that the GFC had almost no impact on per capita GDP. Baird and Wihardja (2010) report some key aspects of the Indonesian economy just after the height of the GFC as follows: GDP growth being dominated by the trade and communications sector; slow recovery in the manufacturing sector with the growth being quite narrow based (dominated by products such as vehicles and chemicals, with wood, paper and printing, basic metals and steel, and textiles and footwear sub-sectors continuing to contract); growth in exports being spurred by high international demand for commodities, coupled with higher prices; and moderate inflationary pressure due to rises in prices from key trading partners. We now turn our focus specifically to Agriculture and Mining, two crucial sectors of the Indonesian economy.

Agriculture has always been essential to Indonesia's economy, with $30 \%$ of Indonesia's land used for Agriculture. The Agriculture sector contributes around 14\% of Indonesia's GDP. The most important agricultural products include palm oil, rubber, cocoa, coffee, tea, cassava, rice and tropical spices, with the lager plantations focusing on the important export products such as palm oil and rubber (Indonesia Investments, 2013). It is the world's largest producer of palm oil. Paddy farming, which produces rice as a staple food for most Indonesians is still the main occupation in rural Indonesia. $29.93 \%$ of households Indonesia are engaged in paddy, corn, soybean and sugar cane farming (Karmini \& Isa, 2103). The agricultural sector contributes $60.49 \%$ to rural household income, with the majority of household income coming from self-employment activities (Lokollo et al., 2007).

Mining accounts for approximately $11 \%$ of Indonesia's GDP, $20 \%$ of its exports, and Indonesia has the world's largest reserve of minerals. The government, realizing that good governance of mining companies is important to attracting foreign investment, has recently issued new regulations which should help new investors obtain mining permits and speed up the issuing of permits to existing investors. Key products include crude petroleum, coal, aluminium, copper and zinc. Associated industries include mining equipment, and financial, legal, software and training services (Business Victoria, 2013).

Figure 1 benchmarks the Indonesian Mining and Agriculture sectors against other key indices. For comparison purposes, all indices are set at 100 in 2004. The IDX has strongly outperformed the US S\&P 500 over the ten years to 2013. Both Agriculture (especially) and Mining experienced large growth up until 2008, 
with huge falls during the GFC. Strong recovery was experienced in all the three Indonesian indices shown in the graph following the GFC, but since 2011 Agriculture has remained fairly static and Mining has fallen below the IDX.

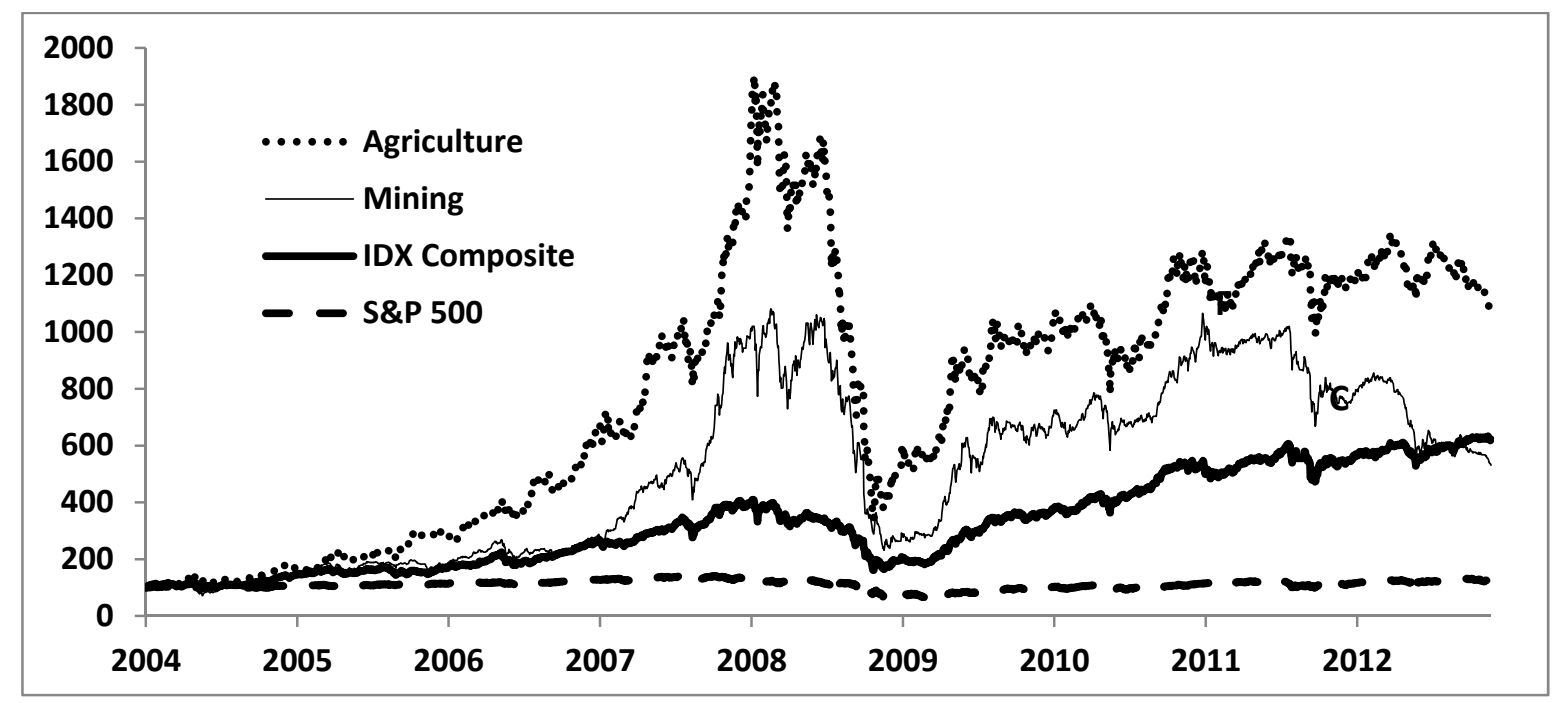

Figure 1. Share market performance

\subsection{Background to the Metrics Used in This Study}

Market Risk is measured in this study using VaR and CVaR. VaR, which measures potential losses over a specific time period within a given confidence level, is a well understood and widely used metric for measuring market risk. The concept has been incorporated into the Basel Accord as a required measurement for determining capital adequacy for market risk.

Despite its wide use, VaR has undesirable mathematical properties; such as lack of sub-additivity (Artzner, Delbaen, Eber, \& Heath, 1997, 1999). Perhaps the biggest shortcoming of VaR is that it is focused on risks below a specified threshold and says nothing of the risks beyond VaR. The measurement has been criticized by Standard and Poor's analysts (Samanta, Azarchs, \& Hill, 2005) due to VaR being applied inconsistently across institutions, as well as lack of tail risk assessment. During the GFC VaR was widely criticized for failing to identify the levels of extreme risk. Conditional Value at Risk (CVaR), on the other hand, measures extreme returns (those beyond VaR). Pflug (2000) proved that CVaR is a coherent risk measure with a number of desirable properties such as convexity and monotonicity, amongst other desirable characteristics. $\mathrm{CVaR}$ has been applied to portfolio optimization problems by several studies (e.g. Andersson, Mausser, Rosen, \& Uryasev, 2000; Rockafellar \& Uryasev, 2002; Uryasev \& Rockafellar, 2000). CVaR has been explored as a measure of sectoral risk (Allen \& Powell, 2011; Allen, Powell, Boffey, Kramadibrata, \& Singh, 2012).

Credit risk in this study is measured using the Distance to Default (DD) structural approach of Merton (1974) and KMV. The model measures DD based on a combination of fluctuating asset values and the debt / equity (leverage structure) of the borrower. Examples of studies using structural methodology for varying aspects of credit risk include predictive value and validation (Bharath \& Shumway, 2008; Stein, 2007); effect of default risk on equity returns (Chan, Faff, \& Kofman, 2008; Vassalou \& Xing, 2004); bank distress (Auvray \& Brossard, 2012); and the measurement of systemic risk Robert Engel (2011). The detailed methodology behind the measurements discussed above, is provided in the following section.

\section{METHODOLOGY}

\subsection{Data}

The data spans 2005 - 2011. To examine differences over varying economic cycles, we split it into three different periods. The first is 2005-2007, which represents the three years prior to the GFC. The second is 2008 which is the height of the GFC. The final period is 2009-2011, which is the three post-GFC years. 
We use all companies on the IDX classified as "Agriculture" and "Mining" using the Global Industry Classification Standard (GICS) codes. Daily share price data is obtained from Datastream, together with the balance sheet data required for measuring DD. We exclude any companies which do not have data spanning the entire period. This yields ten companies for each of Agriculture and Mining which represents approximately $82 \%$ of the total available Agriculture and Mining stocks.

Table 1. Data Sample

\begin{tabular}{lccc} 
& Number & $\begin{array}{c}\text { Market Cap (USD } \\
\$ 000)\end{array}$ & Equity \% \\
\hline Agriculture & 10 & $8,964,031$ & $56 \%$ \\
Mining & 10 & $6,591,861$ & $43 \%$ \\
\hline
\end{tabular}

The final column shows the aggregate book equity ratio for each of the two sectors (total shareholder funds to total assets), as equity is a key component in the DD calculation and these ratios can assist in interpreting our DD figures.

\subsection{Market Risk Measurement}

Our methodology involves calculation of $\mathrm{VaR}$ and CVaR. Value at Risk (VaR) measures the maximum potential losses at a selected threshold (confidence level) over a specified time period. Both parametric and nonparametric options are available in calculating these metrics. Parametric methods assume a normal distribution, which may not be realistic, especially during volatile circumstances such as the GFC. We have therefore chosen the nonparametric historical simulation method, which is based on actual historical figures rather than making any assumption about the distribution. We obtain historical VaR at a 95\% confidence level by sorting the daily returns from best to worst and selecting the 95th return.

Conditional Value at Risk is the risk on condition that it exceeds VaR. If VaR is measured at 95\%, then $\mathrm{CVaR}$ is the average of those $5 \%$ of returns beyond $\mathrm{VaR}$.

\subsection{Credit Risk Measurement}

The Merton-KMV structural approach to estimating distance to default (DD) and probability of default (PD) is used. This model is then modified to incorporate an extreme risk component called Conditional Distance to Default (CDD) and Conditional Probability of Default (CPD). The structural model holds that there are 3 key determinants of default: the asset values of a firm, the risk of fluctuations in those asset values, and the leverage (the extent to which the assets are funded by borrowings as opposed to equity). The firm defaults when debt exceeds equity. DD and PD are measured as follows:

$$
\begin{aligned}
& D D=\frac{\ln (V / F)+\left(\mu-0.5 \sigma_{V}^{2}\right) T}{\sigma_{V} \sqrt{T}} \\
& P D=N(-D D)
\end{aligned}
$$

Where $\mathrm{V}$ is the market value of the firm, $\mathrm{F}=$ face value of firm's debt, and $\mu=$ an estimate of the annual return (drift) of the firm's assets.

Market value of assets is obtained using the approaches outlined by KMV (Crosbie \& Bohn, 2003) and Bharath \& Shumway (2008). Initial asset returns (for every day) in our data set are estimated from our historical equity data (obtained as per section 2.2) using the following equation, where $\mathrm{E}$ is the market capitalization of the firm:

$$
\sigma_{V}=\sigma_{E}\left(\frac{E}{E+F}\right)
$$

The daily $\log$ return is calculated and new asset values estimated every day following the KMV iteration and convergence procedure. We measure $\mu$ as the mean of the change in $\operatorname{lnV}$ as per Vassalou \& Xing (2004). Following KMV, we define debt as current liabilities plus half of long term liabilities. 
Conditional distance to default (CDD) is defined as DD based on the worst $5 \%$ of asset returns. The standard deviation of the worst $5 \%(\mathrm{CStdev})$ is substituted into equation 1 to obtain a conditional DD:

$$
C D D=\frac{\ln (V / F)+\left(\mu-0.5 \sigma_{V}^{2}\right) T}{C^{2 t d e v_{V}} \sqrt{T}}
$$

and

$$
C P D=N(-C D D)
$$

\section{RESULTS AND DISCUSSION}

Table 2. Market and Credit Risk Results

\begin{tabular}{lcccc} 
Agriculture & VaR & CVaR & DD & CDD \\
\hline Pre-GFC & 0.0241 & 0.0375 & 7.4459 & 1.7553 \\
2008 & 0.0711 & 0.1083 & 1.6415 & 0.2348 \\
Post-GFC & 0.0285 & 0.0430 & 8.3541 & 2.4175 \\
Whole Period & 0.0315 & 0.0541 & 7.0059 & 1.3432 \\
\hline & & & & CDD \\
Mining & VaR & CVaR & DD & 1.4001 \\
Pre-GFC & 0.0376 & 0.0622 & 5.2947 & 0.1546 \\
2008 & 0.0771 & 0.1088 & 0.7721 & 1.6826 \\
Post-GFC & 0.0387 & 0.0615 & 6.4282 & 1.3432 \\
Whole Period & 0.0415 & 0.0663 & 5.1344 & CDD \\
\hline & & & & 1.3756 \\
All Sectors (IDX) & VaR & CVaR & 0.3518 & 0.3739 \\
Pre-GFC & 0.0189 & 0.0334 & 2.8621 & 1.3042 \\
2008 & 0.0334 & 0.0525 & 6.4967 & 1.2019 \\
Post-GFC & 0.0201 & 0.0290 & 5.9154 & 0.0424 \\
Whole Period & 0.0266 & & & \\
\hline
\end{tabular}

From a VaR perspective it can be seen that both Mining (especially) and Agriculture have a much higher volatility (significant at the $99 \%$ level using F tests) than the IDX as a whole, across all periods. This is especially evident during 2008 when the volatility for these two sectors was double that of the IDX. A similar picture emerges for $\mathrm{CVaR}$, though more pronounced, with both Mining and Agriculture showing significantly higher CVaR (99\% significance) than the IDX as a whole.

When it comes to credit risk, the picture changes somewhat. Agriculture has a lower credit risk, as measured by both DD and CDD, than the All Sector IDX index for all periods except 2008. Mining, on the other hand, except for 2008, can have either a slightly higher or lower credit risk than the IDX depending on the period or measurement, but overall (except for 2008) the risk is not significantly different to that of the IDX.

The market and credit risk trends and differences are illustrated graphically in Figure 2. The VaR and CVaR graphs show a clear picture of higher risk for the two primary sectors than for the IDX as a whole. This is to be expected. The returns, as illustrated in Figure 1, were much higher in the pre-GFC period for the primary sectors. A fundamental principle of finance is that with higher returns, comes higher risk, and this was illustrated by the large falls for these two sectors over the GFC, and the consistently higher VaR and CVaR for these Sectors, which is exacerbated over the GFC. The DD and CDD graphs show more of a mixed bag. The Agriculture line on the graph remains consistently higher (lower credit risk) than the IDX, except for 2008. The Mining line tends to be somewhat closer to the IDX line, but more volatile. 


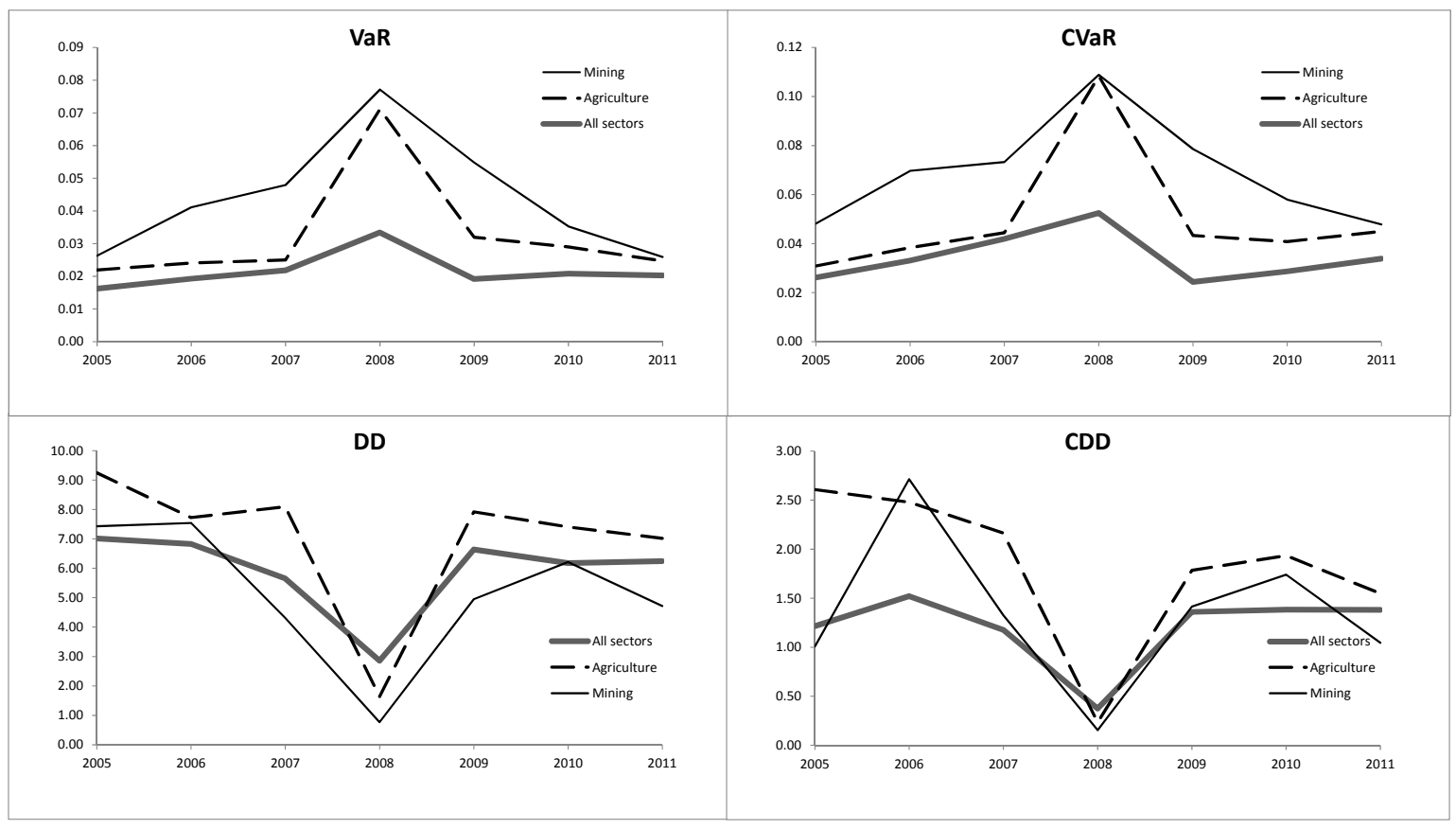

Figure 2. Market and Credit Risk Trends

Why is it that our metrics show consistently higher share market risk for the primary sectors as compared to All Sectors, but no significant differences for credit risk? This is because the DD and CDD metrics also factor in the balance sheet structure of the entities, in addition to market asset volatility. Although there are some complexities in the calculation of DD, in essence, the numerator of the DD calculation is primarily a measure of the relationship between debt and assets (i.e. the equity of the company). In principle, the greater the equity, the more the firm can withstand fluctuations in asset values before the default point is reached. We see in Table 1 that the Agriculture companies have an aggregate equity ratio of $56 \%$ and Agriculture $43 \%$. The weighted average equity ratio of All Sectors on the IDX is much lower at $24 \%$. Some sectors have low equity ratios, particularly banks (where, globally, ratios of $5-10 \%$ are common). Therefore both Agriculture (especially) and Mining are able to weather greater asset fluctuations than most sectors on the IDX. This is why, despite the higher market volatility experienced by these two primary sectors, Agriculture has a lower credit risk (as measured by DD and PD), than All Sectors through most of the studied period and Mining (with exceptions during the GFC period) has a credit risk over the period which is not significantly different to All Sectors. The clear exception is 2008, when the extreme volatility of both sectors overcame their equity advantage as is shown in Figure 2.

\section{CONCLUSION}

Given the importance of the Agriculture and Mining Sectors to the Indonesian economy, this paper set out to determine whether these sectors have higher or lower market and credit risk than the Indonesian market as a whole. This was against a backdrop where, during our pre-GFC period, returns for these two sectors strongly outperformed the market, but where these sectors had savage falls during the GFC, with Agriculture recovering somewhat more strongly than Mining. The market risk for both sectors was consistently found to be higher than for the broader market, with a greater variation between VaR and CVaR during the GFC, showing a higher tail risk for these sectors. The same was not true for credit risk, where for the most part Agriculture credit risk was lower than the market, and Mining credit risk was not significantly different from the market. This is because of the conservative leverage structure of the companies in these sectors, particularly Agriculture, which allows them (with the exception of the 2008 year) to withstand relatively large market asset volatility. These market risk findings are important to investors, showing that higher returns can be gained in these sectors, but these are characterized by higher risk. The credit risk findings are important for lenders (banks) to these sectors. Whereas higher risks to equity investors are usually compensated with potentially higher returns, banks have no such advantage as their returns are capped at a maximum of interest and principal repayments, and it is good for lenders to know that increased volatility, for the most part, has not led to undue credit risk. 
Allen et al. Primary sector volatility and default risk in Indonesia

\section{ACKNOWLEDGEMENTS}

We thank the Australian Research Council and Edith Cowan University for funding support.

\section{REFERENCES}

Allen, D. E., \& Powell, R. J. (2011). Measuring and Optimising Extreme Sectoral Risk in Australia. Asia Pacific Journal of Economics and Business, 15(1), 1-14.

Allen, D. E., Powell, R. J., Boffey, R. R., Kramadibrata, A. R., \& Singh, A. K. (2012). Thumbs Up to Parametric Measures of Relative $\mathrm{VaR}$ and $\mathrm{CVaR}$ in Indonesian Sectors. International Journal of Business Studies, 20(1), 27-42.

Andersson, F., Mausser, H., Rosen, D., \& Uryasev, S. (2000). Credit Risk Optimization with Conditional Value-at Risk Criterion. Mathematical Programming, 89(2), 273-291.

Artzner, P., Delbaen, F., Eber, J. M., \& Heath, D. (1997). Thinking Coherently. Risk, 10, 68-71.

Artzner, P., Delbaen, F., Eber, J. M., \& Heath, D. (1999). Coherent Measures of Risk. Mathematical Finance, 9, 203-228.

Auvray, T., \& Brossard, O. (2012). Too Dispersed to Monitor? Ownership Dispersion, Monitoring, and the Prediction of Bank Distress. Journal of Money, Credit and Banking, 44, 685-714.

Baird, M., \& Wihardja, M. M. (2010). Survey of Recent Developments. Bulletin of Indonesian Economic Studies, 46(2), 143-170.

Bharath, S. T., \& Shumway, T. (2008). Forecasting Default with the Merton Distance-to-Default Model. The Review of Financial Studies, 21(3), 1339-1369.

Business Victoria. (2013). Indonesian Mining Sector - Market Snapshot Retrieved 7 July, 2013, from http://export.business.vic.gov.au/export-markets/countries/malaysia/indonesian-mining-sectormarket-brief

Chan, H., Faff, R., \& Kofman, P. (2008). Default Risk, Size and the Business Cycle: Three Decades of Australian Pricing Evidence Retrieved 16 August 2009 from http://ssrn.com/abstract=1097444

Crosbie, P., \& Bohn, J. (2003). Modelling Default Risk. Retrieved 16 August 2009, from http://www.moodyskmv.com/research/files/wp/ModelingDefaultRisk.pdf

Engel, R. F. (2011). Long Term Skewness and Systemic Risk. Journal of Financial Econometrics, 9(3), 437468.

Indonesia Investments. (2013). Agricultural Sector of Indonesia Retrieved 8 July, 2013, from www.indonesia-investments.com/

Karmini, \& Isa, A. H. M. (2103). The Integrated Planning to Increase Total Housed Income of Paddy Farmers in East Kalimantan, Indonesia Interdisciplinary Journal of Contemporary Research in Business, 4(11), 745-755.

Lokollo, E. M., Rusastra, I. W., Saliem, H. P., Supriati, Friyatno, S., \& Budi, G. S. (2007). Ruralsocioeconomic Dynamics: Comparison Analysis on Agricultural Census. Jakaeta: Ministry of Indonesia.

Merton, R. (1974). On the pricing of corporate debt: The risk structure of interest rates. Journal of Finance, 29, p.p. 449-470.

Pflug, G. (2000). Some Remarks on Value-at-Risk and Conditional-Value-at-Risk. In R. Uryasev (Ed.), Probabilistic Constrained Optimisation: Methodology and Applications. Dordrecht, Boston: Kluwer Academic Publishers.

Rockafellar, R. T., \& Uryasev, S. (2002). Conditional Value-at-Risk for General Loss Distributions. Journal of Banking and Finance, 26(7), 1443-1471.

Samanta, P., Azarchs, T., \& Hill, N. (2005). Chasing Their Tails: Banks Look Beyond Value-At-Risk. . RatingsDirect. Retrieved from http://www2.standardandpoors.com/portal/site/sp/en/us/page.article/2,1,6,4,1126533408950.html

Siregar, H., Hasanah, H., \& Noer, A. A. (2012). Impact of the Global financial Crisis on the Indonesian Economy: Further Analysis using Export and Investment Channels. European Journal of Social Sciences, 30(3), 438-450.

Stein, R. M. (2007). Benchmarking Default Prediction Models: Pitfalls and Remedies in Model Validation. Journal of Risk Model Validation, Spring,1(1), 77-113.

Uryasev, S., \& Rockafellar, R. T. (2000). Optimisation of Conditional Value-at-Risk. Journal of Risk, 2(3), 21-41.

Vassalou, M., \& Xing, Y. (2004). Default Risk in Equity Returns. Journal of Finance, 59, 831-868. 